\title{
SENTINEL-1 AND SENTINEL-2 DATA FUSION FOR WETLANDS MAPPING: BALIKDAMI, TURKEY
}

\author{
Gordana Kaplan ${ }^{1, *}$, Ugur Avdan ${ }^{2}$ \\ ${ }^{1}$ Anadolu University, Remote Sensing and GIS programme, 26555 Eskisehir, Turkey (kaplangorde@ gmail.com) \\ ${ }^{2}$ Anadolu University, Earth and Space Sciences Institute, 26555 Eskisehir, Turkey (uavdan@ anadolu.edu.tr)
}

Commission VI, WG III/6

KEY WORDS: Image Fusion, Sentinel-1, Sentinel-2, Wetlands, Object-Based Classification.

\begin{abstract}
:
Wetlands provide a number of environmental and socio-economic benefits such as their ability to store floodwaters and improve water quality, providing habitats for wildlife and supporting biodiversity, as well as aesthetic values. Remote sensing technology has proven to be a useful and frequent application in monitoring and mapping wetlands. Combining optical and microwave satellite data can help with mapping and monitoring the biophysical characteristics of wetlands and wetlands`vegetation. Also, fusing radar and optical remote sensing data can increase the wetland classification accuracy.

In this paper, data from the fine spatial resolution optical satellite, Sentinel-2 and the Synthetic Aperture Radar Satellite, Sentinel-1, were fused for mapping wetlands. Both Sentinel-1 and Sentinel-2 images were pre-processed. After the pre-processing, vegetation indices were calculated using the Sentinel-2 bands and the results were included in the fusion data set. For the classification of the fused data, three different classification approaches were used and compared.

The results showed significant improvement in the wetland classification using both multispectral and microwave data. Also, the presence of the red edge bands and the vegetation indices used in the data set showed significant improvement in the discrimination between wetlands and other vegetated areas. The statistical results of the fusion of the optical and radar data showed high wetland mapping accuracy, showing an overall classification accuracy of approximately $90 \%$ in the object-based classification method.

For future research, we recommend multi-temporal image use, terrain data collection, as well as a comparison of the used method with the traditional image fusion techniques.
\end{abstract}

\section{INTRODUCTION}

Wetlands provide a number of environmental and socioeconomic benefits such as their ability to store floodwaters and improve water quality, providing habitats for wildlife and supporting biodiversity, as well as aesthetic values. The loss of wetlands which is considered to be more than $50 \%$ since 1900 , has gained considerable attention over the past years. A major cause of wetland loss is considered to be the conversion to agricultural land due to economic and population growth (Berry, Smith et al. 2016). Mapping wetlands have always been of great need since societies depend on natural resources. Wetlands include a range of habitats from permanently flooded areas to seasonally wet areas, both cover with a portion of vegetation. The wetter the wetland area is, the easier it identifies both on the ground and through remote sensing methods.

Remote sensing data such as aerial photo interpretation, satellite imagery or other geospatial data, has proven to be a useful and frequent application in monitoring and mapping wetlands. In the past, aerial photographs have been traditionally used for mapping wetlands, but in the past two decades, multispectral and SAR (Synthetic Aperture Radar) satellite remote sensing data have been effectively used for mapping and monitoring wetlands. Multispectral data has been used for classifying wetlands generally through indices, such as Normalized Difference Vegetation Index (NDVI) (Kayastha, Thomas et al. 2012), Land Surface Water Index (LSWI) (Dong, Wang et al. 2014), Normalized Difference Water Index (NDWI) (Dvorett, Davis et al. 2016), Soil and Atmosphere Resistant Vegetation Index (SARVI) (Huete, Liu et al. 1997), etc. SAR data which are considerably different from optical data, are being collected by active sensors that operate at longer wavelengths and provide different information. C-band operating at 3.75 to $7.5 \mathrm{~cm}$ wavelength has been widely used in wetland mapping (Baghdadi, Bernier et al. 2001, Mleczko and Mróz 2018). The use of SAR data (C-band) has provided overall accuracy of $59 \%$ to $86 \%$ (Baghdadi, Bernier et al. 2001), while the use of optical sensors (Landsat TM) had difficulties separating upper salt marsh from upland forest (Civco, Hurd et al. 2006). Thus, the combination/fusion of both sensors can provide sufficient information for accurately extracting wetlands from the other land covers (Dabrowska-Zielinska, Budzynska et al. 2014).

Sentinel-2A and Sentinel-2B, are a part of the European Copernicus program created by the European Space Agency (ESA) (Sentinel). Sentinel-2 Multispectral Instrument (MSI), is considered to be the follow-up mission to the Landsat instruments, intended to provide continuity of remote sensing products (Malenovský, Rott et al. 2012). In comparison with the latest Landsat OLI/TIRS, Sentinel-2 has better spatial resolution, better spectral resolution in the near infrared region, three Vegetation Red Edge bands with 20-meter spatial resolution, but does not offer thermal data nor panchromatic band. Sentinel-2 MSI sensor compared to existing satellite sensors require adjustment to allow extending actual time series (D'Odorico, Gonsamo et al. 2013). Sentinel-2 offers satellite images with a 
resolution from 10 to 60 meters (Drusch, Del Bello et al. 2012). The Visual and NIR bands have $10 \mathrm{~m}$ spatial resolution, four Vegetation Red Edge and two SWIR bands have $20 \mathrm{~m}$ spatial resolution, while the Coastal aerosol, Water vapour, and Cirrus bands have $60 \mathrm{~m}$ spatial resolution. However, considering the four fine spectral resolution bands, panchromatic band can be produced and used in the Sentinel-2 image fusion for producing ten fine spatial resolution bands (Selva, Aiazzi et al. 2015).

Sentinel-1 is an imaging radar satellite at C-band $(\sim 5.7 \mathrm{~cm}$ wavelength) consisting of a constellation of two satellites, Sentinel-1A and Sentinel-1B, also part of the European Copernicus program created by the ESA. Their main cover applications are: monitoring sea ice zones and the arctic environment; Surveillance of marine environment; Mentoring land surface motion risks; Mapping of land surfaces: forest, water and soil, agriculture; Mapping in support of humanitarian aid on crisis situation (Attema, Davidson et al. 2008, Torres, Snoeij et al. 2012).

In this study, a fusion of Sentinel-1 and Sentinel-2 satellite images has been made for wetland classification. For that purpose, one Sentinel-1 and one Senitnel-2 datasets have been downloaded from the Copernicus Open Access Hub. Before fusing the images from the different sensors, both Sentinel-1 and Sentinel-2 images were pre-processed. The pre-processing of the images includes atmospheric correction and increasing of the spatial resolution from 20 meters to 10 meters of the Sentinel-2 red-edge and shortwave infrared bands, and radiometric calibration, speckle reduction and terrain correction of the Sentinel-1 SAR image. Furthermore, different classification methods have been applied to the common area of the images. Balikdami wetland located in the Anatolian part of Turkey was chosen as a study area. The area of the wetland Balikdami is approximately $30 \mathrm{~km}^{2}$.

\section{METHODS}

\subsection{Study Area and Data}

Sakarya river is the third longest river in Turkey with $824 \mathrm{~km}$ length. Balikdami is one of the wetlands formed along Sakarya riverbed. Located in the Anatolian part in Turkey, Balikdami is unique wetland containing rich flora and fauna and more than 235 bird species. The study area in this paper contains four other wetland areas that were taken into consideration. The image used for classification cover area of approximately $2.200 \mathrm{~km}^{2}$. It is known that this area has been losing its value since the 1980s.

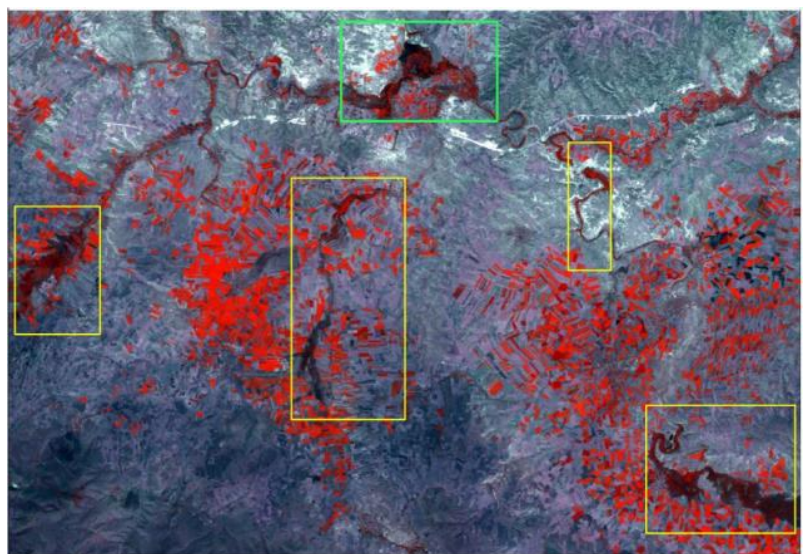

Figure 1. Sentinel-2 image of the study area $(\mathrm{RGB}-8 \mathrm{a}, 4,5)$

Figure 1 shows the study area used in this paper. Also, Balikdami is located in the upper middle part of the Sentinel-2 image marked with green line, while the other wetland areas are marked with yellow colour where. Beside wetlands, agricultural fields, sedimentary rocks, barren lands, bare lands, and open water areas can be found.

For the classification, both Sentinel-1 and Sentinel-2 data were used. For that purpose, the images were downloaded from the Copernicus Data Hub. The images were taken in the summer period when the vegetation in the wetland areas is dense and green which makes it difficult to separate it from other vegetated areas. Sentinel-1 image was taken on 13 August 2017, while Sentinel-2 was taken on 10 August 2017.

\subsection{Pre-processing}

Senintel-1 images need pre-processing before its application. After the download of the image, radiometric and terrain calibration, as well as speckle reduction has been performed. The product has been filtered with Lee Sigma filer $5 \times 5$ window size. For the terrain correction a Range Doppler Terrain Correction with a digital elevation model of $30 \mathrm{~m}$ has been used. The preprocessing has been performed in the SNAP software by ESA using the Sentinel-1 toolbox. The digital number values have been converted into backscattering values in decibel $(\mathrm{dB})$ scale following Equation 1.

$$
\beta^{\circ}{ }_{d b}=10^{*} \log _{10}\left(\beta^{\circ}\right)
$$

Where $\beta^{\circ}$ is the digital number value of the image, and $\beta^{\circ}{ }_{d b}$ is the backscattered value in $\mathrm{dB}$.

The pre-processing of Sentinel-2 product include atmospheric correction and increasing the spatial resolution of the $20-\mathrm{m}$ bands to $10-\mathrm{m}$. In order to increase the spatial resolution of the Vegetation Red-Edge and Short Wave infrared bands, pansharpening techniques should be performed. However, the main pan-sharpening approaches were originally developed for image fusion with a single fine band (Wang, Shi et al. 2016). Sentinel2 provides four $10-\mathrm{m}$ bands that are highly correlated with the 20-m bands. In this study, a single panchromatic band by averaging all fine multispectral bands was produced (Selva, Aiazzi et al. 2015, Wang, Shi et al. 2016). For the pansharpening, a Hybrid Fusion Technique - Wavelet Principal Component (WPC) was used. For the quantitative analyses of the pan-sharpened image, Wald`s protocol was followed which the most widely used one for validation of pan-sharpening methods (Dou 2018). For the quantitative analyses, four indices were used: correlation coefficient (CC) which provides correlation between the fused and the reference image, Universal Image Quality Index (UIQI) which uses covariance, variance, and means of fused and reference image (Pohl and Van Genderen 2016), Relative Average Spectral Error (RASE) (Ranchin and Wald 2000), and Spectral Angle Mapper (SAM), curtail for the case under concern (Kaplan et al. 2018).

\subsection{Methods}

Radar image backscatter values gives valuable information for land cover. Both pre-processed VV and VH Sentinel-1 polarizations were included in the dataset as well as their different combinations such as their average value.

Using the Sentinel-2 bands, several vegetation indexes were calculated: NDVI, NDWI, the Sentinel-2 Red-Edge Position Index (S2REP) (Frampton, Dash et al. 2013), and the Modified Soil Adjusted Index (MSAVI). All of the calculated indices were included in the dataset. 


$$
\begin{gathered}
N D V I=\frac{b 8+b 4}{b 8+b 4} \\
N D W I=\frac{b 3-b 8}{b 3-b 8} \\
S 2 R E P=705+35 *\left[\frac{\left(\frac{b 7+b 4}{2}\right)-b 5}{b 6-b 5}\right] \\
M S A V I=\frac{(b 8-b 4) *(1+L)}{b 8+b 4+L}
\end{gathered}
$$

where the soil adjustment value $\mathrm{L}=0.5$.

The indices were calculated using the pan-sharpened Senitnel-2 bands with a spatial resolution of 10-m. The 60-m Sentinel-2 bands were not included in the dataset. The dataset contains 17 bands that were stacked into single image (Clerici, Valbuena Calderón et al. 2017):

\section{Sentinel-1: VV, VH, $(\mathrm{VV}+\mathrm{VH}) / 2$}

Sentinel-2: Blue, Green, Red, Red-Edge-1, Red-Edge2, Red-Edge-3, NIR, Red-Edge-4, SWIR-1, SWIR-2 Sentinel-2 indices: NDVI, NDWI, S2REP, MSAVI.

Both unsupervised and supervised classification were performed on the dataset. The unsupervised classification was used in order to determine the number of classes that can be distinguished in the study area, while the supervised classification was used for a visual comparison with the object-based classification.

The image was integrated into eCognition software for an objectbased classification. The classification was performed using three main steps: image segmentation, generation of an image object hierarchy, and classification. The image segmentation was done using multi-resolution segmentation, where pixels are grouped into objects (Baatz \& SCHÄPE, 2010). In this study, importance was given to VH, NIR, and SWIR bands since these areas of the electromagnetic spectrum are sensitive to wettnes. The scale parameter determines the maximum possible change of heterogeneity, and it is indirectly related to the size of the created object. Compactness describes the closeness of pixels clustered in an object by comparing it to a circle. The parameters used in this study are given in Table 1 .

\begin{tabular}{lc}
\hline \multicolumn{3}{l}{ Segmentation Settings } \\
\hline Layer Weights & $1 ; 1.2 ; 1 ; 1 ; 1 ; 1 ; 1 ; 1 ; 1.2 ; 1 ; 1 ; 1 ; 1.2 ; 1 ; 1 ; 1 ; 1$ \\
Scale Parameter & 50 \\
Composition of homogeneity criterion \\
\hline Shape & 0.2 \\
Compactness & 0.8 \\
\hline
\end{tabular}

Table 1. Multi-resolution segmentation settings

Afterwards, sample of nine classes were collected using Sentinel2 image: Wetlands - representing low vegetated wetlands, Vegetated wetlands, dense vegetated wetlands - representing marsh with high vegetation, agricultural fields - 1 - representing high vegetated fields, agricultural fields - 2 - representing low vegetated fields, sedimentary rocks, barren land, and bare land. The collected samples were also identified in high-resolution imagery using Google Earth.

The estimation of the classification accuracy assessment was performed based on 129 random points that were used for calculating user and producer accuracy, overall accuracy and kappa statistics.

\section{RESULTS}

\subsection{Sentinel-2 pan-sharpening}

The results from the pan-sharpening over the 20-m Sentinel-2 bands are presented in Figure 2 and Table 2. Both qualitative and quantitative analyses gave satisfactory results of the performed pan-sharpening using the WPC method. It can be easily noticed from Table 1 that all of the quantitative indices calculated were close to the ideal values.
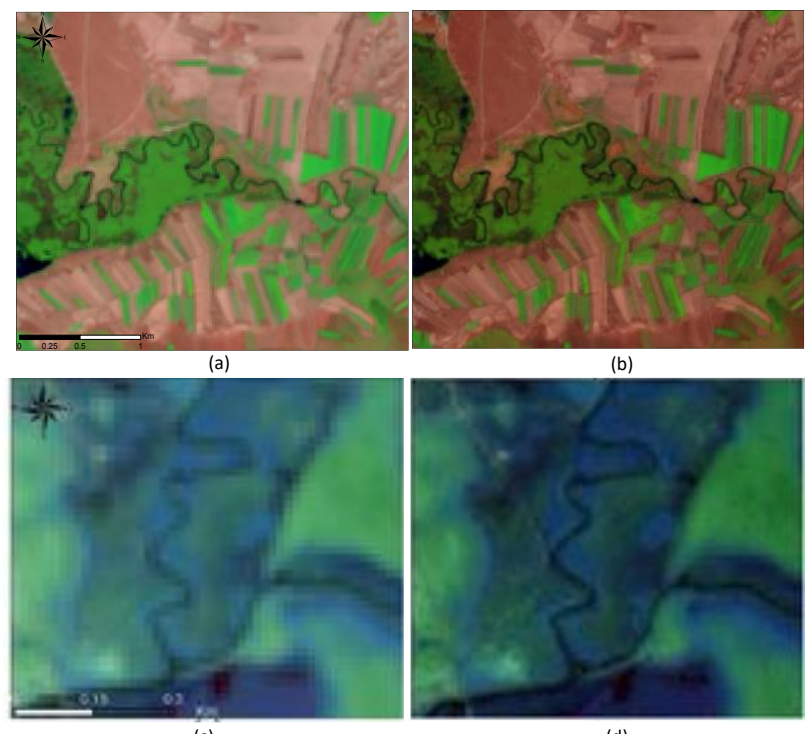

(c)

Figure 2. Sentinel-2 Pan Sharpening results: a) $20 \mathrm{~m}$ (RGB 11,8a,5); b) 10 m (RGB - 11,8a,5); c) 20 m (RGB - 5,11,8a); d) $10 \mathrm{~m}(\mathrm{RGB}-5,11,8 \mathrm{a})$

\begin{tabular}{ccccc}
\hline & CC & UIQI & RASE & SAM \\
\hline Ideal & 1 & 1 & 0 & 0 \\
WPC & 0.966 & 0.956 & 2.70 & 0.026 \\
\hline
\end{tabular}

Table 2. Quantitative analyses of the Sentinel-2 Pan-sharpening

\subsection{Sentinel-1 and Sentinel-2 classification}

The aim of the unsupervised classification was to determine the possible number of classes within the wetland area and the classes that wetlands get mixed up with. The results showed that the wetland area in this study, contains four main classes, low vegetated wetlands, high vegetated wetlands, dense vegetated wetlands, and open water bodies. The results of the 9-classes unsupervised classification showed that low vegetated wetlands get mixed with bare land with small vegetation on the mountains, and wetlands with dense vegetation get mixed with semi vegetated areas in the mountains and some agricultural fields, as well as with open water areas.

After the determination of the number of classes, a supervised classification was performed on the Sentinel dataset. A visual inspection of the supervised classification results versus a natural color composite Sentinel-2 image was made. Although supervised classification results improved the unsupervised classification results, still part of the bare land and the low vegetated fields were mixed with the low vegetated wetlands, and 
part of the high vegetated agricultural fields were mixed with the high vegetated wetlands which can be seen at Figure 3 .

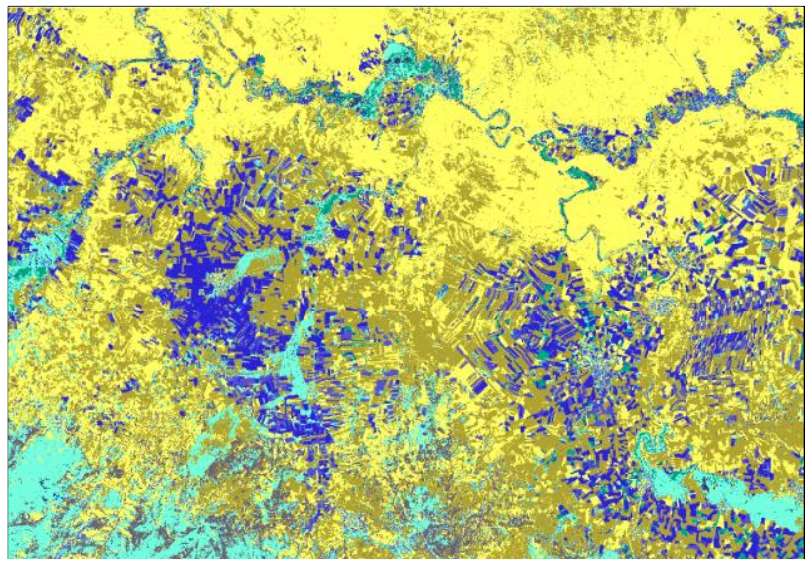

Figure 3. Supervised Classification results

For the object based classification samples from nine classes were collected; wetlands - representing low vegetated wetlands, Vegetated wetlands, dense vegetated wetlands - representing marsh with high vegetation, agricultural fields - 1 - representing high vegetated fields, agricultural fields - 2 - representing low vegetated fields, sedimentary rocks, barren land, and bare land. After the classification visual inspection was made and it was concluded that some agricultural fields that were not classified in neither of the two assigned agricultural classes, thus taking an advantage of the geometry of the objects, an additional condition for a Rectangular Fit of 0.6 was set and new class of agricultural fields was created. The results are presented in Appendix A for the full study area, Figure 4 for the Balikdami wetland area, and the statistical results are presented in Table 2. The overall accuracy was estimated to be more than $89 \%$, while the kappa coefficient was 0.88 . All of the wetland classes had both producer and user accuracy between $85 \%$ and $92.3 \%$. The confusion matrix and more detailed information about the accuracy assessment are given in the Appendix A, Table 3.

\begin{tabular}{|c|c|c|c|c|}
\hline Class & $\begin{array}{l}\text { User } \\
\text { Accuracy } \\
\quad(\%)\end{array}$ & $\begin{array}{l}\text { Commission } \\
\text { Error } \\
\qquad(\%)\end{array}$ & $\begin{array}{c}\text { Producer } \\
\text { Accuracy } \\
(\%)\end{array}$ & $\begin{array}{l}\text { Omission } \\
\text { Error } \\
\quad(\%)\end{array}$ \\
\hline Wetlands & 92.3 & 7.7 & 85.7 & 14.3 \\
\hline Water & 100 & 0 & 100 & 0 \\
\hline Agri-1 & 95.5 & 4.5 & 95.4 & 4.6 \\
\hline Veg_wetland & 90.0 & 10 & 100 & 0 \\
\hline Rocks & 90.9 & 9.1 & 90.9 & 9.1 \\
\hline Dense_wet & 87.5 & 12.5 & 87.5 & 12.5 \\
\hline Barren Land & 87.5 & 12.5 & 82.3 & 17.7 \\
\hline Bare Land & 95.2 & 4.8 & 80.0 & 20 \\
\hline Agri-2 & 100 & 0 & 75.0 & 25 \\
\hline Agri-3 & 72.7 & 27.3 & 100 & 0 \\
\hline \multicolumn{2}{|c|}{ Overall accuracy } & $89.15 \%$ & & \\
\hline \multicolumn{2}{|l|}{ Kappa } & 0.88 & & \\
\hline
\end{tabular}

Table 2. Classification accuracy assessment
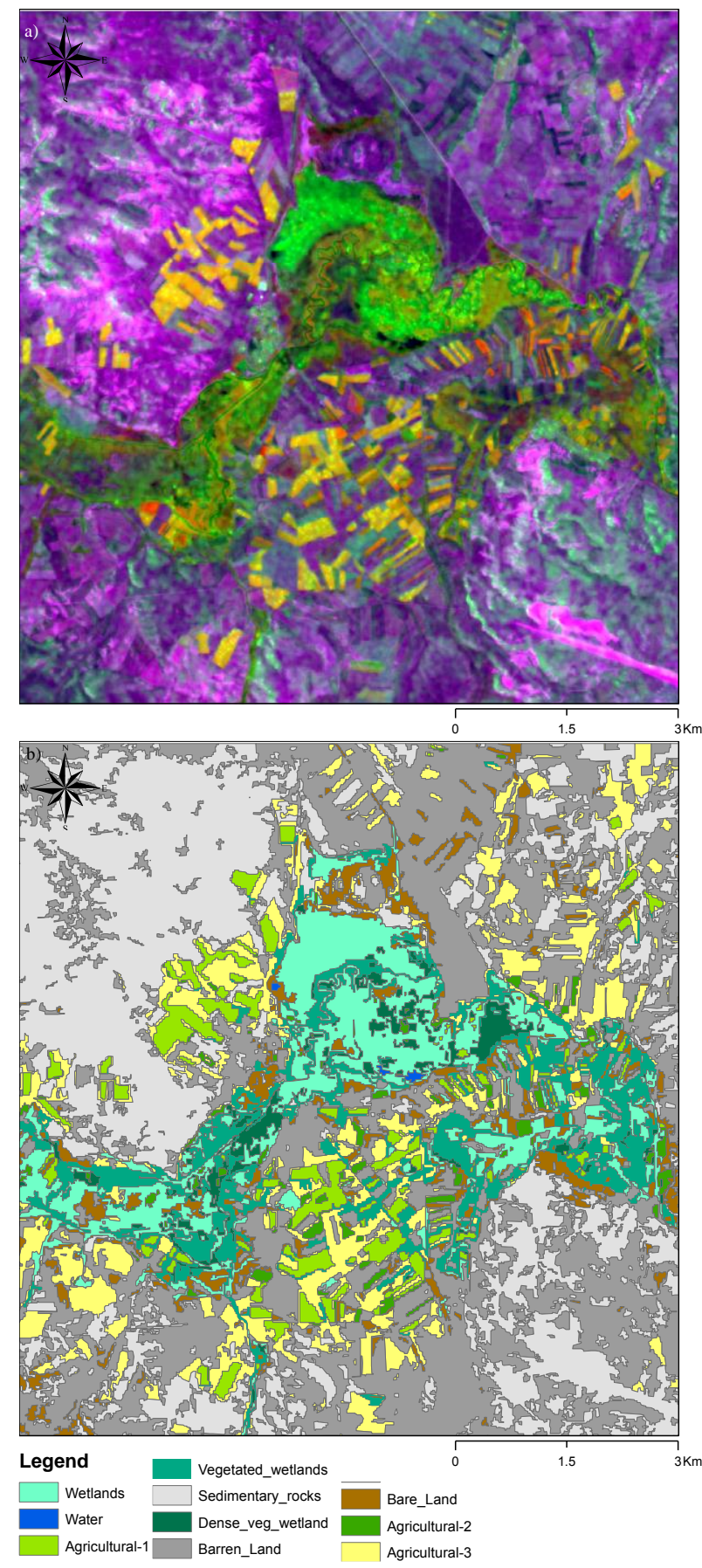

Figure 4. a) Data Set (RGB - NIR, VH, Red); b) Classification results of Balikdami wetland

\section{CONCLUSION}

The complex structure of wetlands, makes it difficult to classify wetlands using remote sensing data. Both multispectral and radar data have advantages and disadvantages in wetland mapping and monitoring. Combining these different sensors and using their advantages, in this paper, we fused Sentinel-1 and Sentinel-2 and achieved overall accuracy of more than $89 \%$. Still, some of the wetlands areas were mistakenly classified as agricultural areas which could be fresh watered fields. However, this allegation needs to be confirmed by ground control points. 


\section{ACKNOWLEDGMENTS}

This study was supported by Anadolu University Scientific Research Projects Commission under the grant no: 1705F121.

\section{REFERENCES}

Attema, E., M. Davidson, N. Floury, G. Levrini, B. Rosich, B. Rommen and P. Snoeij (2008). Sentinel-1 ESA's new European radar observatory. Synthetic Aperture Radar (EUSAR), 2008 7th European Conference on, VDE.

Baghdadi, N., M. Bernier, R. Gauthier and I. Neeson (2001). "Evaluation of C-band SAR data for wetlands mapping." International Journal of Remote Sensing 22(1): 71-88.

Berry, P., A. Smith, R. Eales, L. Papadopoulou, M. Erhard, A. Meiner, A. Bastrup-Birk, E. Ivits, E. R. Gelabert and G. Dige (2016). "Mapping and assessing the condition of Europel's ecosystems: progress and challenges-EEA contribution to the implementation of the EU Biodiversity Strategy to 2020."

Civco, D., J. Hurd, S. Prisloe and M. Gilmore (2006). Characterization of coastal wetland systems using multiple remote sensing data types and analytical techniques. IEEE Int. Conf. Geosci. Remote Sens. Symp. 2006 (IGARSS 2006).

Clerici, N., C. A. Valbuena Calderón and J. M. Posada (2017). "Fusion of Sentinel-1A and Sentinel-2A data for land cover mapping: a case study in the lower Magdalena region, Colombia." Journal of Maps 13(2): 718-726.

D'Odorico, P., A. Gonsamo, A. Damm and M. E. Schaepman (2013). "Experimental Evaluation of Sentinel-2 Spectral Response Functions for NDVI Time-Series Continuity." Ieee Transactions on Geoscience and Remote Sensing 51(3): 13361348 .

Dabrowska-Zielinska, K., M. Budzynska, M. Tomaszewska, M. Bartold, M. Gatkowska, I. Malek, K. Turlej and M.

Napiorkowska (2014). "Monitoring wetlands ecosystems using ALOS PALSAR (L-Band, HV) supplemented by optical data: A case study of Biebrza Wetlands in Northeast Poland." Remote Sensing 6(2): 1605-1633.

Dong, Z. Y., Z. M. Wang, D. W. Liu, K. S. Song, L. Li, M. M. Jia and Z. Ding (2014). "Mapping Wetland Areas Using Landsat-Derived NDVI and LSWI: A Case Study of West Songnen Plain, Northeast China." Journal of the Indian Society of Remote Sensing 42(3): 569-576.

Dou, W. (2018). "Image Degradation for Quality Assessment of Pan-Sharpening Methods." Remote Sensing 10(1): 154.

Drusch, M., U. Del Bello, S. Carlier, O. Colin, V. Fernandez, F. Gascon, B. Hoersch, C. Isola, P. Laberinti and P. Martimort (2012). "Sentinel-2: ESA's optical high-resolution mission for GMES operational services." Remote Sensing of Environment 120: $25-36$

Dvorett, D., C. Davis and M. Papes (2016). "Mapping and Hydrologic Attribution of Temporary Wetlands Using Recurrent Landsat Imagery." Wetlands 36(3): 431-443.

Frampton, W. J., J. Dash, G. Watmough and E. J. Milton (2013). "Evaluating the capabilities of Sentinel-2 for quantitative estimation of biophysical variables in vegetation." ISPRS journal of photogrammetry and remote sensing 82: 8392.

Huete, A., H. Liu, K. v. Batchily and W. Van Leeuwen (1997). "A comparison of vegetation indices over a global set of TM images for EOS-MODIS." Remote sensing of environment 59(3): 440-451.

Kaplan, G.; Avdan, U. Sentinel-2 Pan Sharpening \&ndash; Comparative Analysis. In Proceedings of the 2nd International Electronic Conference on Remote Sensing, 22 March-5 April 2018; Sciforum Electronic Conference Series, Vol. 2, 2018; doi:10.3390/ecrs-2-05158

Kayastha, N., V. Thomas, J. Galbraith and A. Banskota (2012). "Monitoring Wetland Change Using Inter-Annual Landsat Time-Series Data." Wetlands 32(6): 1149-1162.

Malenovský, Z., H. Rott, J. Cihlar, M. E. Schaepman, G. García-Santos, R. Fernandes and M. Berger (2012). "Sentinels for science: Potential of Sentinel-1,-2, and-3 missions for scientific observations of ocean, cryosphere, and land." Remote Sensing of environment 120: 91-101.

Mleczko, M. and M. Mróz (2018). "Wetland Mapping Using SAR Data from the Sentinel-1A and TanDEM-X Missions: A Comparative Study in the Biebrza Floodplain (Poland)." Remote Sensing 10(1): 78.

Pohl, C. and J. Van Genderen (2016). Remote Sensing Image Fusion: A Practical Guide, Crc Press.

Ranchin, T. and L. Wald (2000). "Fusion of high spatial and spectral resolution images: The ARSIS concept and its implementation." Photogrammetric Engineering and Remote Sensing 66(1): 49-61.

Selva, M., B. Aiazzi, F. Butera, L. Chiarantini and S. Baronti (2015). "Hyper-sharpening: A first approach on SIM-GA data." IEEE Journal of Selected Topics in Applied Earth Observations and Remote Sensing 8(6): 3008-3024.

Sentinel, E. "Delivers First Images." Available onlin e: http://www. esa. int/Our_Activities/Observing the Earth/Copernicus/Sentinel-2/Sentinel2_delivers_first_images (accessed on 7 January 2016).

Torres, R., P. Snoeij, D. Geudtner, D. Bibby, M. Davidson, E. Attema, P. Potin, B. Rommen, N. Floury, M. Brown, I. N. Traver, P. Deghaye, B. Duesmann, B. Rosich, N. Miranda, C. Bruno, M. L'Abbate, R. Croci, A. Pietropaolo, M. Huchler and F. Rostan (2012). "GMES Sentinel-1 mission." Remote Sensing of Environment 120: 9-24.

Wang, Q., W. Shi, Z. Li and P. M. Atkinson (2016). "Fusion of Sentinel-2 images." Remote sensing of environment 187: 241 252. 
The International Archives of the Photogrammetry, Remote Sensing and Spatial Information Sciences, Volume XLII-3, 2018 ISPRS TC III Mid-term Symposium “Developments, Technologies and Applications in Remote Sensing”, 7-10 May, Beijing, China

\section{APPENDIX A}

Table 3. Confusion matrix and classification accuracy assessment

\begin{tabular}{|c|c|c|c|c|c|c|c|c|c|c|c|c|c|c|}
\hline Land Cover & 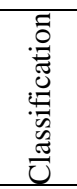 & 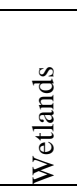 & 离 & 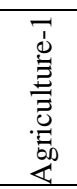 & 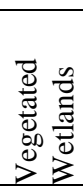 & 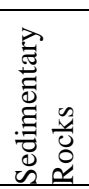 & 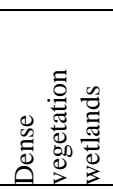 & 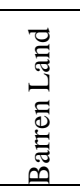 & 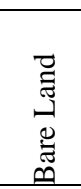 & 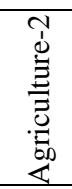 & 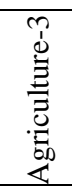 & స్유 & 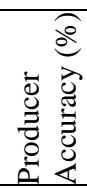 & 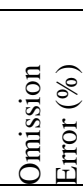 \\
\hline Wetlands & & 12 & 0 & 0 & 0 & 0 & 0 & 0 & 0 & 1 & 0 & 13 & 85.7 & 14.3 \\
\hline Water & & 0 & 3 & 0 & 0 & 0 & 0 & 0 & 0 & 0 & 0 & 3 & 100 & 0 \\
\hline Agriculture-1 & & 0 & 0 & 21 & 0 & 0 & 1 & 0 & 0 & 0 & 0 & 22 & 95.4 & 4.6 \\
\hline Vegetated Wetl & lands & 0 & 0 & 1 & 9 & 0 & 0 & 0 & 0 & 0 & 0 & 10 & 100 & 0 \\
\hline Sedimentary R & ocks & 0 & 0 & 0 & 0 & 10 & 0 & 1 & 0 & 0 & 0 & 11 & 90.9 & 9.1 \\
\hline Dense vege wetla & ands & 1 & 0 & 0 & 0 & 0 & 7 & 0 & 0 & 0 & 0 & 8 & 87.5 & 12.5 \\
\hline Barren Land & & 0 & 0 & 0 & 0 & 1 & 0 & 14 & 1 & 0 & 0 & 16 & 82.3 & 17.7 \\
\hline Bare Land & & 1 & 0 & 0 & 0 & 0 & 0 & 0 & 20 & 0 & 0 & 21 & 80 & 20 \\
\hline Agriculture-2 & & 0 & 0 & 0 & 0 & 0 & 0 & 0 & 0 & 3 & 0 & 3 & 75 & 25 \\
\hline Agriculture-3 & & 0 & 0 & 0 & 0 & 0 & 0 & 2 & 4 & 0 & 16 & 22 & 100 & 0 \\
\hline Total & & 14 & 3 & 22 & 9 & 11 & 8 & 17 & 25 & 4 & 16 & 129 & & \\
\hline User Accuracy & $(\%)$ & 92.3 & 100 & 95.5 & 90 & 90.9 & 87.5 & 87.5 & 95.2 & 100 & 72.7 & \multicolumn{3}{|c|}{$\begin{array}{c}\text { Overall accuracy } \\
89.15 \%\end{array}$} \\
\hline $\begin{array}{l}\text { Commission } \\
(\%)\end{array}$ & Error & 7.7 & 0 & 4.5 & 10 & 9.1 & 12.5 & 12.5 & 4.8 & 0 & 27.3 & \multicolumn{3}{|c|}{ Карра 0.88} \\
\hline
\end{tabular}

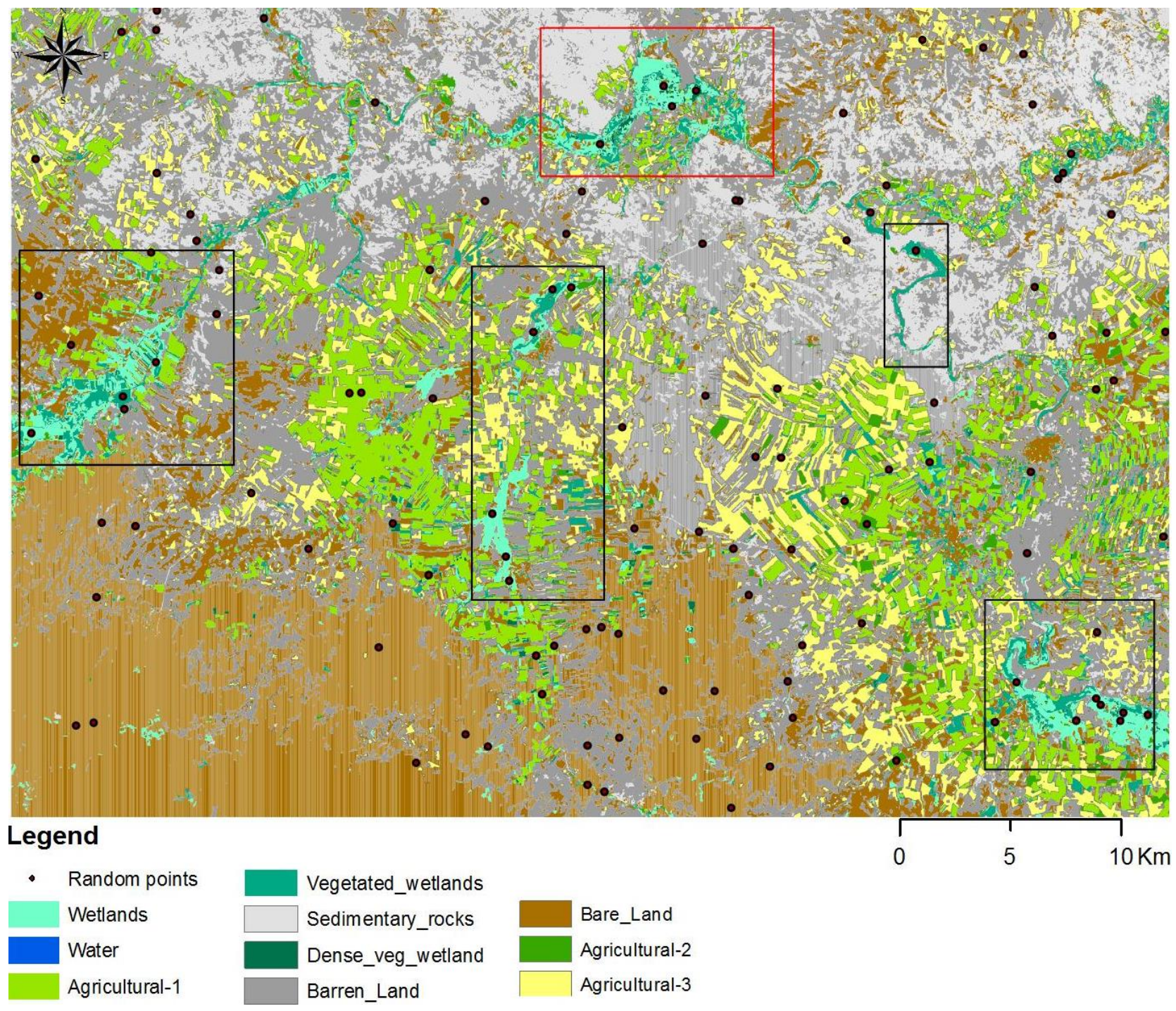

Figure 5. Classification results of the full study area 